\title{
Objetivação e positividade na Vida de Jesus de G.W.F. Hegel
}

\author{
Dalpícolo, André C.*
}

10 de agosto de 2008

\begin{abstract}
Resumo
Resumo: Este trabalho pretende examinar a relação entre objetivação e positividade na Vida de Jesus (1795), de G.W. F. Hegel. Para isso, mostrar-se-á como a objetivação refere-se à faculdade humana de se exteriorizar junto ao meio circundante em sua totalidade (natureza e sociedade). O desenvolvimento satisfatório dessa objetivação corresponde a conciliação religiosa do homem com Deus, posto que revela a autêntica face da objetividade. Todavia, esse desenvolvimento é interrompido pelo desejo do povo judeu de recuperar o esplendor de seu Estado. Assim, os judeus fundamentam uma falsa objetividade (a positividade) em detrimento daquela inspirada por Deus. Por isso, a tarefa de Jesus Cristo é ensinar ao homem a importância de desenvolver sua objetivação, visto que somente assim superará o mal que circunda sua historicidade. O resultado disso é a crucificação do filho de Deus pelas mãos das autoridades judias.

Palavras-chave:

Hegel, Objetivação, Positividade, Vida de Jesus

Abstract: This work intends to analyse the relationship between objectivation and positivity in The Life of Jesus (1795), by G. W. F. Hegel. For this, it will show how the objectivation refers to the human faculty of exteriorizing itself alongside the surrounding environment in its totality (nature and society). The satisfactory development of this objectivation corresponds to the religious conciliation of the man with God, given that it reveals the authentic face of objectivity. However, this development is interrupted by the Jews' desire to recover the splendour of their State. Therefore, the Jews establish a false objectivity (the positivity) to the detriment of the one inspired by God. For this reason, Jesus Christ's task is to teach the man the importance of developing his objectivation, since only by doing this he will overcome the evil around his historicity. The result of this is the crucifixion of God's son by the Jew authorities hands.

Keywords:

Hegel, Objectivation, Positivity, Life of Jesus
\end{abstract}

* Mestre em Filosofia pela PUC-SP e Doutorando pelo Departamento de Filosofia e Metodologia das Ciências, da Universidade Federal de São Carlos , UFSCAR. Orientador Prof ${ }^{\underline{O}}$ Dro ${ }^{\mathrm{o}}$ José Eduardo Marques Baioni. Agência financiadora: CAPES. 
Os escritos de juventude de G.W.F. Hegel são ensaios e fragmentos relacionados essencialmente a assuntos religiosos que durante muito tempo permaneceram inéditos, pois somente alguns extratos foram publicados pelos biógrafos hegelianos K. Rosenkranz ${ }^{1}$ e R. Haym ${ }^{2}$. Em 1905, o alemão W. Dilthey ${ }^{3}$ realizou um extenso comentário acerca desses escritos cujo resultado foi a renovação do pensamento hegeliano: "Parece que o quadro vivo e fascinante da formação do pensamento hegeliano manifestado por Dilthey foi o verdadeiro ponto de partida da renovação hegeliana que marca o início deste século" (ASVELD, 1953, p. 1). Também contribuiu para essa renovação a coletânea de textos juvenis escritos por G. W. F. Hegel e organizada em 1907 por H. Nohl ${ }^{4}$. Para S. G. Noriega, deve-se chamá-la de Hegelrenaissance, posto que modificou a direção geral dos estudos hegelianos: "É sabido que os 'escritos teológicos' tem modificado consideravelmente a direção geral dos estudos hegelianos, sobretudo na França e na Alemanha, dando origem à denominada Hegelrenaissance" (NORIEGA, 1975, p. 8). Em linhas gerais, a Hegelrenaissance consiste na mudança radical de enfocar a filosofia hegeliana, visto que ressalta a diasteme ${ }^{5}$ em detrimento do sistema. Assim, ela "abre caminho para uma nova interpretação da Fenomenologia como obra culminante da preocupação antropológica hegeliana e centro focal de sua produção (Hyppolite, Kojève)" (NORIEGA, 1975, p. 8). Na Alemanha, os principais estudos dedicados aos escritos de juventude de G.W.F. Hegel são de autoria de Th. Haring ${ }^{6}$, H. Glockner ${ }^{7}$, Th. Steinbüchel ${ }^{8}$ e G. Lukács ${ }^{9}$. Na França, o célebre Le malheur de la conscience dans la philosophie de Hegel $^{10}$ revelou pela primeira vez a importância dos textos juvenis hegelianos. Após isto, ocorreu uma série de estudos destinados a compreensão da filosofia do jovem G.W. F. Hegel, entre os quais se destacam os de J. Hyppolite ${ }^{11}$, P.

\footnotetext{
${ }^{1}$ ROSENKRANZ, K. G. W. F. Hegel's Leben. Berlin, 1844.

${ }^{2}$ HAYM, R. Hegel und seine Zein. Berlin, 1857.

${ }^{3}$ DILTHEY, W. Die Jungendschriften Hegels. Berlin, 1905. Utilizaremos neste artigo a tradução espanhola Hegel y el idealismo. Tradução de Eugenio Imaz. México: FCE, 1944.

${ }^{4}$ NOHL, H. Hegels theologische Jugendschriften. Tübigen, 1907. Convém observar que esta coletânea foi completada por Hoffmeister, J. Dokumente zu Hegels Entwicklung. Stuttgart, 1936.

${ }^{5}$ Expressão utilizada originariamente por G. Jarczyk e P.-J.Labarrière no texto De Kojève à Hegel: 150 ans de pensée hégélienne em France. Paris: Albin Michel, 1996.

${ }^{6}$ HARING, Th. Hegel, sein Wollen und sein Werke. Leipzig, 1929.

${ }^{7}$ GLOCKNER, H. Hegel, Stuttgardt, 1929 (I) e Stuttgart 1940 (II).

${ }^{8}$ STEINBÜCHEL, Th. Das Grundproblem der Hegelschen Philosophie. Bonn, 1933.

${ }^{9}$ LUKÁCS, G. Der junge Hegel. Uber die Beziehungen von Dialektik und Ökonomie. Zürich-Wien, 1948. Utilizaremos neste artigo a tradução francesa Le jeune Hegel. Introdução e Tradução de Robert Legros e Guy Haarscher. Paris: Gallimard, 1981.

${ }^{10}$ WAHL, J. Le malheur de la consciente dans la philosophie de Hegel. Paris, 1929.

${ }^{11}$ Existem dois textos fundamentais de J. Hyppolite acerca dos escritos de juventude de G.W.F. Hegel. O primeiro é o artigo Les travaux de jeunesse de Hegel d'après des ouvrages récents. In: Revue de Métaphysique et de Morale, Paris, juillet et octobre 1935. O segundo é o livro Introduction à la philosophie de l'histoire de Hegel. Paris, 1948. Utilizaremos neste artigo a tradução portuguesa Introdução à filosofia da história de Hegel. Tradução de José Marcos Lima. Lisboa: Edições 70, 1995.
} 
Bertrand $^{12}$, H. Nohl ${ }^{13}$, P. Asveld ${ }^{14}$ e B. Bourgeois ${ }^{15}$.

II

G. W. F. Hegel termina seus estudos de teologia no outono de 1793 e se recusa a seguir a carreira de pastor, já que não possui a voz e tampouco os gestos de um orador. Por isso, vê-se obrigado a trabalhar como preceptor de crianças ricas e preencher o seu tempo com a publicação de trabalhos que possam lhe oferecer a oportunidade de iniciar a carreira acadêmica. Do mesmo modo que ocorreu com J. G. Fichte e alguns alemães de sua época, G. W. F. Hegel estabelece-se na Suíça e começa a trabalhar como preceptor da família von Steiger que pertence à aristocracia berniense. Segundo W. Dilthey, "Hegel serviu como professor doméstico durante sete anos - três em Berna e quatro em Frankfurt - até que a morte de seu pai lhe trouxe a liberdade em forma de uma pequena herança. Ao contrário do que aconteceu com Schleimecher e Herbart, ele não conheceu o aspecto agradável e educativo que podia dar-se em tais circunstâncias" (DILTHEY, 1944, p. 23). No período de Berna (1793-1796), G.W.F. Hegel não publicou seus escritos, apesar de dar-lhes uma certa valoração: "Hegel jamais publicou os textos redigidos em Berna entre 1793 e 1796 " a primeira obra impressa que traz o seu nome é datada de 1801 -, mas ele confere uma certa importância aos mesmos, já que os conservou cuidadosamente durante toda sua vida" (LEGROS, 1987, p. 10). O ensaio Vida de Jesus ${ }^{16}$, redigido entre maio e julho de 1795, representa o único estudo completo do período de Berna e foi publicado por $\mathrm{H}$. Nohl a partir de manuscritos conservados na Biblioteca de Berlim. O propósito desse ensaio é detalhar a harmonização dos Evangelhos segundo os relatos bíblicos do apóstolo Lucas, uma vez que os mesmos estão adequados aos princípios expostos pela religião racional. Nota-se, portanto, que a "Vida de Jesus" apresentada por G. W. F. Hegel se aproxima do "Novo Evangelho Eterno" exposto por G. E. Lessing em meados do século XVIII. Na obra Nathan der Weise, o teólogo alemão ataca a valoração excessiva que algumas doutrinas cristãs conferem à figura histórica de Jesus Cristo enquanto personagem da Santa Trindade (Gott mit uns), posto que isto faz obscurecer a distinção entre o elemento histórico e o eterno de toda religião. Assim, ele acredita que o essencial de toda forma religiosa é a verdade eterna que o homem descobre por si mesmo e não através de milagres e graças oferecidas por Jesus Cristo: "O essencial da religião é comum a todas as religiões, ou seja, as verdades eternas que elas trazem consigo e que todo homem bem nascido pode descobrir por si mesmo" (ASVELD, 1955, p. 20). Entretanto, engana-se aquele

\footnotetext{
${ }^{12}$ BERTRAND, P. Le sens du tragique et du destin dans la dialectique hégélienne. In: Revue de Métaphysique et de Morale, Paris, avril, 1940.

${ }^{13}$ NOHL, H. De la médiation dans la philosophie de Hegel. Paris, 1945.

${ }^{14}$ ASVELD, P. La pensée religieuse du jeune Hegel. Paris: Desclée de Brouwer, 1955.

${ }^{15}$ BOURGEOIS, B. Hegel a Francfort ou Judaïsme, Christianisme et Hegelianisme. Paris: J. Vrin, 1970.

${ }^{16}$ G. W. F. HEGEL, Das Leben Jesu - Harmonie der Evangelien nach eigenen Übersetzung. Tubigen, 1907. Utilizaremos neste artigo a tradução espanhola Historia de Jesus. Introdução e Tradução de Santiago Gonzáles Noriega. Madrid: Taurus, 1975.
} 
que faz de G. E. Lessing o protagonista de uma religião racional que rejeita o cristianismo. Em seu último livro Die Erziehung des Menschengeschlechtes, ele reinterpreta a história da raça humana através do modelo da história cristã da salvação e observa nessa história a preparação para o surgimento da "autêntica humanidade". Aos seus olhos, Jesus Cristo é verdadeiramente o filho de Deus do mesmo modo que toda a humanidade. Por isso, G. E. Lessing expõe que o essencial de toda religião (inclusive do cristianismo) está contido na célebre fórmula do apóstolo João: "Minhas pequenas crianças, amais-vos uns aos outros" (JOÃO, apud ASVELD, 1955, p. 20).

\section{III}

Um melhor entendimento da Vida de Jesus realizar-se-á à medida que se refletir acerca da objetivação humana na filosofia do jovem G. W. F. Hegel. Decerto, essa idéia não ganhou os seus contornos finais no período em que o filósofo alemão residia na cidade de Berna, mas é inegável que sua preocupação central era pensar a vida humana: "'Pensar a vida: eis a tarefa', disse Hegel num fragmento de juventude" (HYPPOLITE, 1955, p. 13). Logo, não é equivocado apontá-la como a exteriorização do homem junto ao meio circundante. De acordo com G. W. F. Hegel, a característica essencial da objetivação humana é a consolidação da autonomia moral do sujeito ${ }^{17}$. Para ele, tudo o que Deus fez foi criar o mundo livremente e com conhecimento de causa. Assim, o desígnio da divindade é que o homem aja segundo sua natureza, isto é, em prol da moralidade: "O homem honra Deus ao tomar consciência de sua vontade que se exprime na natureza e na conformidade da condição humana ao seu estado natural" (ASVELD, 1955, p. 15). No entanto, isto somente se realizará caso Deus não interfira no curso do Universo, quer seja através de graças ou de punições atribuídas aos existentes. Caso contrário, corre-se o risco do humano perder seu atributo mais fundamental, ou seja, a autonomia moral. Por esta razão, o jovem G. W. F. Hegel critica toda religião que submete a condição humana a uma série de ritos que procuram legitimar a interferência divina no Universo. No ensaio Vida de Jesus, o filósofo alemão procura revelar o equívoco dessa submissão, uma vez que a mesma afasta o homem de Deus, ao invés de aproximá-lo18: "O céu e a terra podem perecer, mas não as exigências da lei moral e tampouco o dever de obedecê-la. Quem se exime a si mesmo e aos demais não é digno de levar o nome de cidadão do reino de Deus, mas quem as cumpre e ensina aos outros a respeitá-las será estimado no reino celestial" (HEGEL, 1975, p. 36). Tem-se de esclarecer que a autonomia moral do sujeito é um fenômeno supra-individual, uma vez que o objetivo do jovem G. W. F. Hegel é pensar a vida humana em todas as suas manifestações históricosociais. Parafraseando J. Hyppolite, pode-se dizer que ela é uma realidade ao mesmo tempo individual e universal, visto que se apresenta no mundo sob a forma de um povo ${ }^{18}$. Para tanto, faz-se necessário indicar que a autonomia

\footnotetext{
${ }^{17}$ G. W. F. HEGEL, Das Leben Jesu ? Harmonie der Evangelien nach eigenen Übersetzung. Tubigen, 1907. Utilizaremos neste artigo a tradução espanhola Historia de Jesus. Introdução e Tradução de Santiago Gonzáles Noriega. Madrid: Taurus, 1975.

${ }^{18}$ Cf. HYPPOLITE, Jean. Introdução à filosofia da história de Hegel, op. cit., p.19.
} 
moral do sujeito desenvolve uma racionalidade distinta dos princípios abstratos do entendimento calculador ${ }^{19}$, isto é, da reflexão que contrapõe a sensibilidade em relação à razão. Para G. W. F. Hegel, essa racionalidade é a centelha de divindade que o homem carrega consigo, já que revela sua aproximação com Deus: "A razão é a 'centelha' ou a 'faísca' da divindade que foi conferida ao homem por Deus, enobrecendo-o e elevando-o até o divino" (NORIEGA, 1975, p. 15). A primeira atitude dela é combater o equívoco do período histórico que busca, através de ritos e crenças, glorificar a intervenção de Deus no curso do Universo. Um dispositivo que auxilia nessa glorificação é a memória, já que atualiza a produção de uma falsa objetividade cuja essência não está conforme o desenvolvimento autêntico da objetivação humana: "A memória é a potência na qual são enforcados os deuses gregos. Ela é a queda, o lugar onde se revitaliza isto que é morto" (HEGEL, apud LUKACS, 1981, p. 112). Nota-se, portanto, que a racionalidade proposta pelo jovem G. W. F. Hegel corrobora muitos pontos defendidos pela filosofia prática de Kant, sobretudo no que diz respeito ao cuidado de identificar a moralidade com a essência da religião. Aliás, esse cuidado torna o ensaio Vida de Jesus o escrito mais "kantiano" produzido pelo jovem G. W. F. Hegel ${ }^{20}$, visto que nele Jesus Cristo representa o porta-voz da fé moral exposta pela filosofia kantiana na obra Die Religion innerhalb der Grenzen der blossen Vernunft: "A Vida de Jesus tem um fim prático e serve para a realização de sua religião popular. A doutrina de Cristo se modifica em direção a fé moral de Kant e o exemplo de Cristo deverá comunicar força a esta fé racional" (DILTHEY, 1944, p. 26). A segunda atitude tomada pela racionalidade defendida por G. W .F. Hegel é preservar algumas particularidades que são próprias a qualquer período histórico, inclusive daquele marcado pela crença da interferência divina no Universo. Certamente a mais importante delas é capacidade da imaginação popular estimular a realização da forma ideal de governo, isto é, da república. Não é errôneo acrescentar que esse estímulo desqualifica o princípio mais abstrato do entendimento calculador, ou seja, o individualismo, porque fundamenta os cânones do espírito de um povo (Volksgeist). Assim, o ensaio Vida de Jesus favorece " inspirando-se em J.-J. Rousseau " uma religião subjetiva em detrimento de uma religião objetiva, posto que procura legitimar a manifestação religiosa que inspira no homem a realização das melhores ações morais: "A religião subjetiva, que se assemelha à religião do vicário saboiano, opõe-se ao mesmo tempo ao racionalismo seco e abstrato de um Voltaire e à teologia positiva de uma religião autoritária; é uma religião do coração, capaz, diz Hegel, 'de inspirar as maiores ações, porque age sobre o homem como um todo e não unicamente sobre sua razão"” (HYPPOLITE, 1995, p. 21).

\section{IV}

\footnotetext{
${ }^{19}$ Expressão utilizada originariamente por R. Legros na introdução dos Fragments de la période de Berna.

${ }^{20}$ Esta é a opinião de S. A. Noriega: ?História de Jesus é a obra de maior fidelidade kantiana produzida por Hegel, a tal ponto de Haring considerá-la um parênteses no desenvolvimento da temática hegeliana, pois ?se destaca do caráter dos escritos precedentes e subseqüentes?? (NORIEGA, 1975, p. 9).
} 
O objetivo da Vida de Jesus é mostrar o equívoco da falsa objetividade (a positividade), ou melhor, da "...supressão da autonomia moral do sujeito" (LUKÁCS, 1981, p. 99). Porém, os dois motivos que fundamentaram essa falsa objetividade foram expostos por G. W. F. Hegel no fragmento berniense Chaque peuple eut ses propres objets de l'imagination ${ }^{21}$. O primeiro deles foi o abandono, por parte dos atenienses e dos romanos, da idéia do Estado como produto da atividade do cidadão. Sabe-se que eles obedeciam as leis e os governantes escolhidos livremente e por isso acreditavam que a realização do Estado era o telos fundamental de suas vidas, ou melhor, o "(...) propósito final do mundo ou então de seus mundos - que se encontrava presente na realidade onde eles contribuíam para presentear e conservar" (HEGEL, 1987, p. 98) ${ }^{22}$. Em face disso, a individualidade destes cidadãos desaparecia diante da necessidade de perpetuar esse telos. Todavia, o acréscimo de riquezas provocado pelas guerras motivou tanto em Atenas quanto em Roma a formação de uma classe de pessoas "a aristocracia" que começou a advogar em benefício próprio. Desse modo, a finalidade essencial do cidadão ateniense ou romano não era mais a preservação do Estado, mas sim a de sua própria individualidade. A partir deste instante, surgiu o temor perante a morte pelo fato dela representar o fim da existência humana 23: "A morte, este fenômeno que dilacera o enredo de seus propósitos, a atividade de toda sua vida, deve the aparecer agora como algo assustador, pois lhe revela que nada sobreviverâ" (HEGEL, 1987, p. 100). O segundo desses motivos foi a crença dos judeus na existência de um libertador. Os componentes do Estado judeu jamais ficaram na espera do Messias para restituir-lhes a dignidade moral. No entanto, a invasão de algumas nações estrangeiras, sobretudo a romana, motivaram nos judeus o sentimento de impotência diante da perda da liberdade. Assim, eles procuraram nos livros sagrados determinados elementos que mostrassem a força do Messias para libertá-los do jugo dos opressores. Em contrapartida, tinham que acreditar na chegada desse Messias a qualquer instante, pois somente assim recuperariam a liberdade.

Cabe ao ensaio Vida de Jesus mostrar a importância dos judeus substituírem essa crença pela máxima universal da moralidade ${ }^{24}$. Desse modo, eles poderão retomar o desenvolvimento da dignidade moral que os fundamenta. De acordo com a mensagem de Jesus Cristo, os judeus conseguirão realizar essa substituição caso desqualifiquem a hipocrisia que rege atualmente seus espíritos. Parafraseando P. Bertrand, pode-se dizer que o objetivo do filho de Deus é salvar o povo judeu de si mesmo ${ }^{25}$. Para que isso ocorra, faz-se necessário que os judeus

\footnotetext{
${ }^{21}$ Convém observar que G. W. F. Hegel não intitulou a maioria dos fragmentos redigidos no período de Berna. Por isso, recorremos a classificação descrita por $\mathrm{R}$. Legros na obra Fragments de la période de Berne: ?Hegel não intitulou os diferentes textos que nos chegaram de forma fragmentada. Com o intuito de não impor uma orientação particular e por cuidado de simplificar, todos os títulos que atribui aos fragmentos são formados a partir dos primeiras palavras do texto alemão? (LEGROS, 1987, p. 11).

${ }^{22}$ Citação ligeiramente modificada por mim, A. C. D.

${ }^{23}$ Convém observar que os gregos e romanos acreditavam que suas ações permaneciam por toda a eternidade, uma vez que trabalhavam em prol da conservação do Estado.

${ }^{24}$ Para G. W. F. Hegel, essa máxima é ?faça aos demais aquilo que gostaria que fizessem com você? (HEGEL, 1975, p. 40, nota 24).

${ }^{25}$ Cf. BERTRAND, P. Le sens du tragique et du destin dans la dialectique hégélienne, In,
} 
abandonem a excessiva valoração que conferem a certas tradições cujo desígnio é revelar o poder libertador do Messias, tais como a purificação do corpo e o descanso semanal obrigatório. Contudo, é importante observar que toda estrutura sócio-econômica do Estado judeu estava fundamentada na idéia da chegada do Messias, apesar desse Estado estar sob a custódia de Roma. Assim, nota-se que Jesus Cristo despertou o ódio das autoridades judias, sobretudo dos escribas e dos fariseus, uma vez que pretendia alterar o status quo vigente através da dialética do amor: "Deus pede amor e não sacrifícios" (HEGEL, 1975:44). Por fim, o resultado deste ódio foi a crucificação de Jesus Cristo: "Depois que havia gritado que tinha sede e depois de ter tomado um pouco de vinagre que lhe foi oferecido numa esponja, disse: 'Está consumado' e logo em seguida disse em voz mais alta: 'Pai, em tuas mãos encomendo meu espírito', inclinou a cabeça e morreu" (HEGEL, 1975:94).

\section{Referências}

[1] ASVELD, P. La pensée religieuse du jeune Hegel. Paris: Desclée de Brouwer, 1953.

[2] BERTRAND, Pierre. Le sens du tragique chez Hegel. Paris: Revue de Métaphysique et de Morale, n⿳丷ㅡㄹ Abril 1940, pp. 165-186.

[3] DILTHEY, W. Hegel y el idealismo. Tradução de Eugênio Imaz. México: FCE, 1944.

[4] HEGEL, G. W. F. Escritos de juventud. Tradução e Introdução de J.M. Ripalda. México: FCE, 1978.

[5] _ __. Fragments de la període de Berne. Introdução de Robert Legros e Trădução de Fabienne Verstraeten e Robert Legros. Paris: J. Vrin, 1987.

[6] ___. L'esprit du christianisme et son destin. Introdução de J. Hyppolite e Tradução de J. Martin. Paris: J.Vrin,1988.

[7] _ _ . Historia de Jesus. Tradução e Introdução de S. G. Noriega. Madrid: Taurus, 1975.

[8] HYPPOLITE, Jean. Introdução à filosofia da história de Hegel. Tradução de José Marcos Lima. Lisboa: Edições 70, 1995.

[9] LEGROS, R. Hegel a Berne - Introdução des Fragments de la període de Berne. In: HEGEL, G. W. F. Fragments de la període de Berne. Introdução de Robert Legros e Tradução de Fabienne Verstraeten e Robert Legros. Paris: Vrin, 1987, pp.7-32.

[10] LUKÁCS, Wihleim. Le jeune Hegel. Tradução e Introdução de Gay Haarscher e Robert Legros. Paris: Gallimard, 1981.

op. cit., p. 172 . 
[11] NORIEGA, S. G. Introdução da Historia de Jesus. In: HEGEL, G. W. F.

Historia de Jesus. Tradução e Introdução de S. G. Noriega. Madrid: Taurus, 1975, pp. 9-22. 